\title{
Effect of Psychodrama Therapy on Depression and Anxiety of Juvenile Delinquents
}

\author{
Niharika Sharma $^{1} *$
}

\section{ABSTRACT}

The purpose of this study was to study the effect of psychodrama therapy on depression and anxiety level of juvenile delinquent. 20 juvenile delinquents were selected through accidental sampling from reformatory school of Gorakhpur (U.P.). The subjects were participated in an eight-session psychodrama therapy plan for 8 weeks in a group. In order to collect data, the Beck depression inventory II and Zung self rating anxiety scale was applied. Data analysis was performed by paired $t$ test. The $t$ test results revealed that there is a significant difference between psychodrama and depression and anxiety of juvenile delinquent. Psychodrama therapy significantly decreases the level of depression and anxiety of juvenile delinquent.

Keywords: Psychodrama, Depression, Anxiety, Juvenile Delinquent.

A child is born with innocence and if nurtured with tender care and attention, then they grow in positive way physical, mental, moral and spiritual development of children make them capable of realizing their fullest potential. On the opposite side, harmful surroundings, negligence of basic needs, wrong company and other abuse may turn a child to juvenile delinquent.

Children constitute about $40 \%$ of India's population and India has a national policy for children declaring children to be a national assets. Unfortunately, the crime of child increasing at an alarming rate day by day. There has been $47 \%$ increase in crime committed by children between 2010 to 2014. Juvenile crime registered under Indian panel code (IPC), from 22,740 cases in 2010 to 33,526 cases in 2014 according to data released by national crime record bureau. As against an overall total no. of 28.51 .536 cases resisted in the country. When cases that were filled under special local law were added to the IPC data the total no. of cases against juveniles shot up to 48,230 . About $75 \%$ of those accused in these cases were in the age group of 16-18 years.

Juvenile delinquent behaviour is one of the most important issues we face as a nation in this millennium. Juvenile delinquency is an astronomic problem in India by which most of the

\footnotetext{
${ }^{1}$ Research Scholar, Dept. of Clinical Psychology, Dev Sanskriti Vishwavidyalya, Hardwar, India *Responding Author

(C) 2017 Sharma N; licensee IJIP. This is an Open Access Research distributed under the terms of the Creative Commons Attribution License (www.creativecommons.org/licenses/by/2.0), which permits unrestricted use, distribution, and reproduction in any Medium, provided the original work is properly cited.
} 


\section{Effect of Psychodrama Therapy on Depression and Anxiety of Juvenile Delinquents}

youth ruin their lives. Because of juvenile crime and relate problem, youth, their families and the entire society suffer multiple consequences.

Crimes committed by children and adolescents under the age of 18 years, is called delinquency. The maximum age limit and also the meaning of delinquency vary from country to country. But it is also below 18 years that is statutory. In India any person between the age of 7 and 18 years who violates the provisions of children act, the IPC and CPO will be considered as delinquent. Person above this age are considered as criminal. Delinquency is behaviour of youth under 18 years of age which is not acceptable to society and is generally regarded as calling for some kind of admonishment, punishment or corrective actions (Coleman, 1981).

The word delinquency is derived from the Latin world 'delinquere' and meaning of this word is to leave. Originally, the word had an objective meaning as it referred to parents who neglected and abandoned their children. Delinquency is an act and conduct of a juvenile which is socially undesirable. Juvenile delinquency generally means the failure of children to meet certain obligations expected of them by society. The juvenile delinquency is expression of unsatisfied desires and urges.

Delinquency begins in the young adolescence stage. This is a time of identity crisis. Many adolescents find it quite frightening to develop an identity. The adolescents live at the intersection point of three levels. At the biological level, there are hormonal and physical changes of puberty. The second level is psychological level at which there is the inner struggle for identity and intense change in desires and moods. The third level is sociocultural level, at this level there are conflicting demands of family, school and various peer group. The modern values are in conflicting shape and social life has developed much complexities. These all affect the adolescents in his search of identity. So the adolescents undergoes through the periods of stress and strain in the search for his identity, protection and guidance. In the absence of these he develops a feeling of neglect and insecurity. Many times such feelings lead him to think that he is uncared in the world and thus he develops antisocial attitudes which result in his delinquent act.

According to Allman (1973), "that category is a match to all of adolescent problem, ranging from less serious and temporary experimentation with sexually and drug, to the very serious failure of forming personal identity, social alienation or even suicide". Hence we can say that mental health difficulties play an important role in delinquent act. Mental health difficulties are linked directly and indirectly to later delinquency.

It is rather common to speak of delinquents as being disturbed in various degrees as according to various descriptive distinctions, such as emotionally, mentally, seriously or severely. A good proportion of them, however, are not disturbed in a sense that has special significance for the psychiatrist and some of them should not be called 'disturbed' at all. They have symptoms involving impulsiveness, anger, cognitive confusion, unmanageable 


\section{Effect of Psychodrama Therapy on Depression and Anxiety of Juvenile Delinquents}

behaviour and a great risk to themselves or others, especially under the stress associated with their offence and arrest.

According to Glueck and Glueck theory delinquency is a symptom of emotional maladjustment. Many delinquents are emotionally disturbed (Glueck, S., 1950). Emotional instability would be expected to multiply with the antisocial conduct. It has been reported by many researchers that the crimes like murder and rape are mainly the crimes of emotionality (Johnson, 1996, Gibsbons, 1968). As mentioned by Friedlander (1945) many delinquents not only have a long history of severe frustration, they also react aggressively to stress situations. Juvenile delinquents are emotionally unstable and lacking in ability to control and adjust themselves, and therefore express their desires wildly and aggressively. Repetitive negative experiences, frustration, and conflicts lead them to committing delinquency and second offenses. Most juvenile delinquents have experienced severe rejection from their parents at an early period of their life or trauma like the loss of their parents or those important to them. As a result, they try not to form meaningful relationships with others and scarcely expect care and consideration from others (Hunt \& Weiner, 1982). Juvenile delinquents do not appropriately express themselves relative to normal adolescents, feel anxious because they fail to properly respond to small stresses in their ordinary routines, are impulsive, and are highly aggressive, and behave with irrational ways of thinking (Jang, 2001).

At this time only punishment is not discussed as a treatment method because it is no longer viewed as a viable technique of treatment through some feel that pain serves as a deterrant to further criminal action.

Prevention is necessary for such children, because without treatment they may continue on a path of delinquency and eventually adult crime. Effective treatment can help to break this cycle and produce healthier young who are less likely to act out and commit crime.

Psychodrama is a branch of art therapy, providing a different vision in the field of psychotherapy. In the early 1920s, this procedure was introduced by Moreno as the result of his discoveries on personal conflicts as to release suppressed emotions. Psychodrama is a relationship-oriented approach that helps people to discover the psychological dimensions of their problem; in this case, the individual concerns his problems not only by dialogues, but also by visualizing them. Among the most important values of psychodrama is to teach skills that go beyond the task of problem solution. This approach seeks to treat social and mental health issues which may be due to the lack of critical communication skills including dialogue, interpersonal skills, and self-awareness.

Previous studies have shown that Psychodrama is effective for the treatment of moderate depression (Hamamci, 2006), the treatment of addicted girls at risk of sexual abuse for coping with trauma (Somov, 2008 ) and to reduce the amount of somatization, anxiety, depression and overall general health promotion (Ghasenpoor et al., 2010). 


\section{Effect of Psychodrama Therapy on Depression and Anxiety of Juvenile Delinquents}

So the researcher has a query that psychodrama decrease level of anxiety and depression in juvenile delinquents. Hence this study was completed to answer that query and tried to give a contribution for welfare of juvenile delinquent

\section{Objective of present study}

1. To study the effect of Psychodrama on the level of depression of juvenile delinquents.

2. To study the effect of Psychodrama on the level of anxiety of juvenile delinquents.

\section{Hypotheses}

1. There is no significant effect of psychodrama on the level of depression of juvenile delinquents.

2. There is no significant effect of psychodrama on the level of anxiety of juvenile delinquents.

\section{METHOD}

\section{Sample plan}

In the present study 20 participants were selected through accidental sampling from Reformatory school of Gorakhpur (Uttar Pradesh). In the present study, researcher included in the sample only those participants who were between 16 to 18 years old and their qualification atleast $8^{\text {th }}$ standard. Researcher included in the sample only those participants who lived in the reformatory school atleast for the three months time period and also those participants who had moderate level of anxiety and depression symptoms base on their score on BDI II and Zung self rating anxiety scale. In the present study, researcher did not include in the sample those participants who had mental illness, physical illness and any type of drug addiction.

\section{Research design}

In the present study pre test- post test single group design has been used.

\section{Measures}

1. Beck Depression Inventory (BDI-II): This scale was developed by Aaron T. Beck in 1996. This scale consist 21 questions. It has high degree of reliability 0.89. This inventory measures cognitive, affective, somatic symptoms, neurovegetative and endogenous aspects of depression.

2. Zung Self Rating Scale: The test used to measure the level anxiety. This scale was developed by William W. K. Zung in 1971. This scale consist 20 questions. The internal consistency reliability coefficient was found .80 .

\section{Procedure}

Pilot study- A pilot study was conducted on 40 delinquents. In this study there was schedule an interview session for the identification of the exactly psychological problem exists in delinquents. And find that depression and anxiety were the main problem in them. 
After seeking the permission by concerned authorities of Uttar Pradesh Women and Child Welfare Department, at the initial stage 20 delinquents were identified and approached for participation in the study. There were administered two different psychological measures (BDI II, Zung Self Rating Anxiety Scale) on them. The results obtained at this point were constituted pre test score. BDI II and Zung self rating scale were in English language and participants of the present study have problem with English language as they were not highly educated. So researcher had needed to translate the scale into Hindi language.

For the translation of scale, first BDI II and Zung self rating anxiety scale were translated into Hindi language without losing the concept of items by an expert in Hindi language. The Hindi translation of the scales was back translated into English by an independence translator who is equally competent in both languages. There is no difference between the original English and back translated English language scale. Hence the Hindi language scale was found to be satisfactory for this study. For the psychometric properties of these test researcher selected a sample of 40 students (20 male, 20 female) of age group 13 to 14 years. Then filled the BDI II and Zung anxiety scale in both language respectively by them. After that calculated Pearson's correlation coefficient between the scores of both language scales of BDI II and Zung anxiety scale. Hence reliability of BDI II and Zung anxiety scale were found to be 0.74 and 0.80 respectively. These values showed that translated version is fairy reliable for the particular study.

After taking pre test, session of psychodrama was conducted for 60 days according to schedule. Psychodrama once in a week for two or three hours, it includes three techniques as self presentation, role reversal and future projection.

First session was a warm up and introduction of member and provided some description about psychodrama, its technique, rules and structure. Second and third session was self presentation, by this; the effort was to establish a dialogue and define the problem in the group, in addition to building confidence, practicing speaking skills and catharsis. Fourth and fifth session was role reversal that emphasised on the verbal and non verbal way to understand feelings, familiarity with body language, trying to develop mental abilities through innovation and awareness of emotions in oneself and others, reinforced feeling of joy, sadness and speech behaviour training and also focused on encouraging the member to tell their problem and to participate as a helper in casting process and behaviour exercise. Sixth and seventh session was future projection, future scene was enacted for the purpose of rehearsal, confronting fears, practising a hoped for outcome, testing expectation also tried to modify their feeling, perception, attitude and behaviour that could be create problem in their future life. Significant change in thinking and rational knowledge was able to provide psychological balance. Eighth session as a termination session, in addition to the review and conclusion of activity session and discussion on achievement, the members addressed their plan for the continuation of life. 


\section{Effect of Psychodrama Therapy on Depression and Anxiety of Juvenile Delinquents}

Again same psychological measures were administered to delinquents who completed the course of intervention program successfully. The results obtained at this point were constituted the post test score.

At the administration of intervention program, some delinquents left the jail during the intervention because of this it took large number of patients and longer time for data collection.

\section{RESULT}

Under This section of research work, deals with the statistical analysis of data and its interpretation as well as discussion of the obtained results. As pointed out in preceding section, the following table has been drawn.

1.1There is no significant effect of psychodrama on the level of depression of juvenile delinquents.

\begin{tabular}{|l|l|l|l|l|l|l|l|}
\hline Group & $\mathbf{N}$ & Mean & SD & r & SE $_{\mathbf{D}}$ & Df & t-value \\
\cline { 1 - 3 } Pre test & 20 & 38.2 & 7 & \multirow{2}{*}{0.25} & \multirow{2}{*}{1.73} & \multirow{2}{*}{19} & \multirow{2}{*}{$2.83^{*}$} \\
\hline Post test & 20 & 33.3 & 5.29 & & & & \\
\hline
\end{tabular}

* Significant at .05 level

It is observed from Table that the Mean score of pre-test is 38.2 with Standard Deviation 7 and the Mean score of post-test is 33.3 with Standard Deviation 5.29. The correlation coefficient is 0.25 and standard error of deviation is 1.73 . The calculated ' $t$ ' value is 2.83 which is significant at 0.05 level of confidence. Hence null hypothesis has been rejected. It indicates that there is a significant effect of psychodrama on level of depression of juvenile delinquents.

It also observed from the result table that the mean value of the post test condition is smaller than the value of pre test condition. It means the psychodrama significantly decreases the level of depression of juvenile delinquents.

Bar diagram shows the mean and standard deviation of depression level of juvenile delinquents.

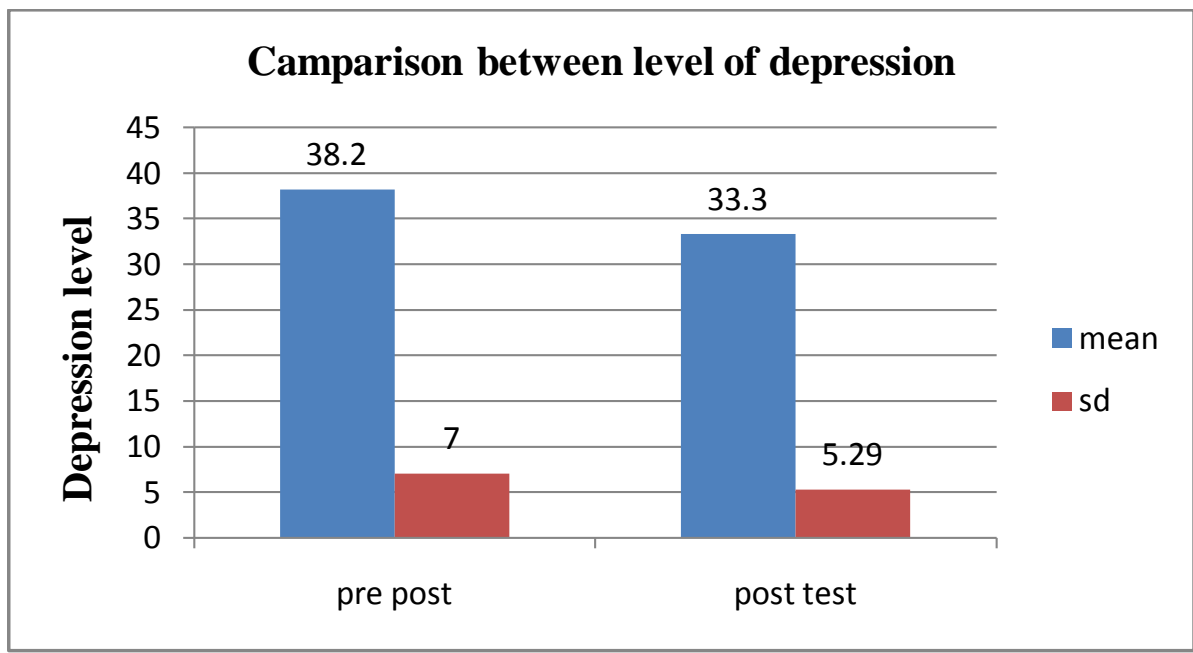

(C) The International Journal of Indian Psychology, ISSN 2348-5396 (e)| ISSN: 2349-3429 (p) | 43 
1.2 There is no significant effect of psychodrama on the level of anxiety of juvenile delinquents.

\begin{tabular}{|l|l|l|l|l|l|l|l|}
\hline Group & $\mathbf{N}$ & Mean & SD & $\mathbf{r}$ & SE $_{\mathbf{D}}$ & Df & t-value \\
\hline Pre test & 20 & 38 & 9.27 & \multirow{2}{*}{0.12} & 2.5 & 19 & $3.23^{* *}$ \\
\hline Post test & 20 & 29.9 & 7.41 & & & & \\
\hline
\end{tabular}

** Significant at .01 level

It is observed from Table that the Mean score of pre-test is 38 with Standard Deviation 9.27 and the Mean score of post-test is 29.9 with Standard Deviation 7.41. The correlation coefficient is 0.12 and standard error of deviation is 2.5. The calculated 't' value is 3.23 which is significant at 0.01 level of confidence. Hence null hypothesis has been rejected. It indicates that there is a significant effect of psychodrama on level of anxiety of juvenile delinquents.

It also observed from the result table that the mean value of the post test condition is smaller than the value of pre test condition. It means psychodrama significantly decreases the level of anxiety of juvenile delinquents.

Bar diagram shows the mean and standard deviation of anxiety level of the juvenile delinquents.

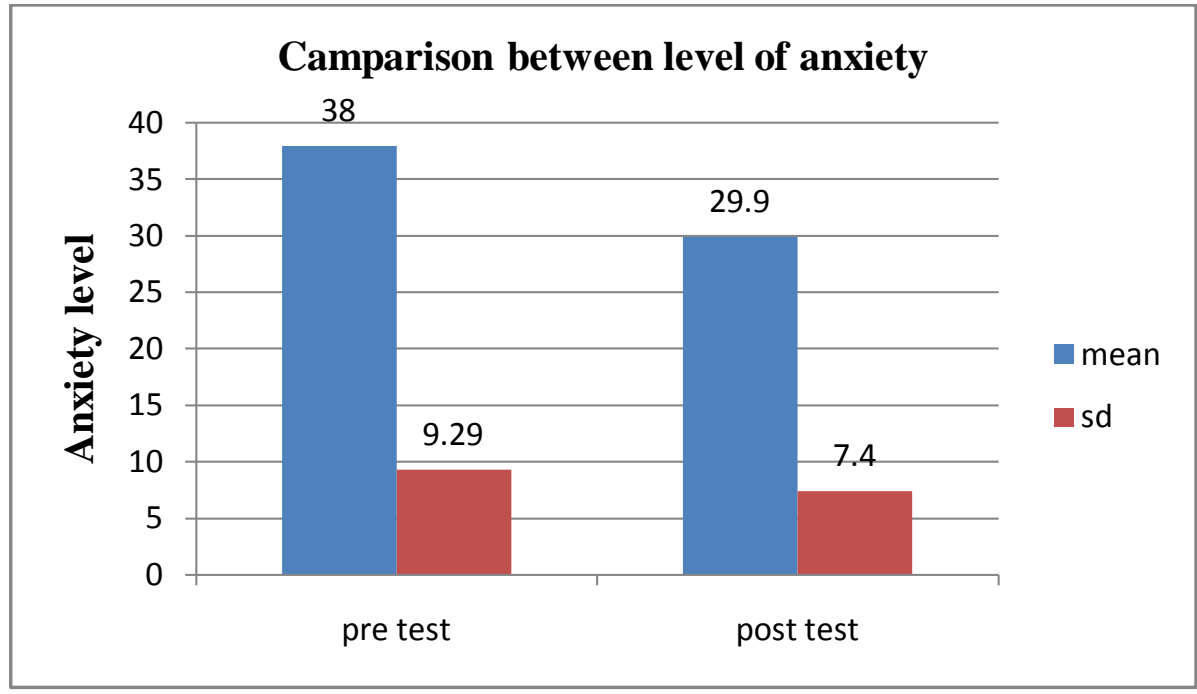

\section{DISCUSSION AND INTERPRETATION}

The objective no. 1 was, to study the effect of psychodrama on the level of depression of juvenile delinquents. In order to study our objective researcher has formulated nullhypothesis i.e. there is no significant effect of psychodrama on the level of depression. Based on the obtained results, the null-hypothesis is rejected at 0.01 level of confidence. It means there is a significant effect of psychodrama on the level of depression of juvenile delinquent. Based on the mean value it concludes that psychodrama significantly decrease the level of depression of juvenile delinquents. 


\section{Effect of Psychodrama Therapy on Depression and Anxiety of Juvenile Delinquents}

Delinquents with depressive symptoms reported some problem like hopelessness, loneliness, isolation, repressed emotion, lack of self confidence and self esteem. Depression demonstrates a variety of symptoms, such as mood, emotional, cognitive, motivational and physical signs (Rosenhan, 1995).

Psychodrama is a group therapy modality for the aim of behaviour modification as well as relation oriented approach. Psychodrama can lead to reduction of depression symptoms by using different technique like self presentation, role reversal and future projection that motivate them to speak and play with others. During psychodrama meetings, people learned to take the intuitive and excitedly made relationships with others (Rajabi, 2007). By these process changes in cognition insight, understanding self strength, provide an opportunity to experience and repeats life situation and facts. After catharsis and sharing, they are feeling good and positive.

Result of the present study supported by previous study of Ebrahimi (2011), studied psychodrama practice with the women in depression and at the end of the study he reached significant results over depression. Ozdel et al (2010) found significant decrease in patients' depressive symptoms and increases in coping with stress and re-interpreting the incidents positively in the psychodrama practice. Therefore the participation in psychodrama treatment demonstrated clinical improvement in depression symptoms (Rosenhan and Seligman, 1995).

The objective no. 2 was, to study the effect of psychodrama on the level of anxiety of juvenile delinquents. In order to study our objective researcher has formulated nullhypothesis i.e. there is no significant effect of psychodrama on the level of anxiety. Based on the obtained results, the null-hypothesis is rejected at 0.01 level of confidence. It means there is a significant effect of psychodrama on the level of anxiety of juvenile delinquent. Based on the mean value it concludes that psychodrama significantly decrease the level of anxiety of juvenile delinquents.

Delinquent with anxiety disorder reported some problem like nightmares or fear at bed time and have difficulty falling as sleep, worry, conflict, tension over every day events as well as future adjustment.

Psychodrama is a treatment method, in this method delinquent rather than speak about its own conflicts, it deals with practical implementation. By self presentation, role reversal and future projection, they can release their inner emotion such as anger, conflict, sadness, fear and tension. Thus they feel encouragement and hope. They can identify himself better and face with conflicts and gets ready that with a better understand of himself and others, plays new roles and processes himself and implements them in real life situations. In overall determination we can infer to an original nature of psychodrama. Several researches conclude that this group therapy, for overcoming this anxiety and style changing of emotional expression are accepted and are necessary (Dadsetan, 2008). According to data and their interpretation we can consider the psychodrama as an effective method in reducing anxiety 


\section{Effect of Psychodrama Therapy on Depression and Anxiety of Juvenile Delinquents}

among juvenile delinquents that it can creates a significant and sustainable change in anxiety and emotional expressiveness. From important goals of psychodrama, we can point to facilitate the release of trapped emotions, helping to authorities to acquire new and more effective behaviours, opening unresolved ways for problem solving and solving the conflicts (Akbari, 2012).

Result of the present study supported by previous study of Hall (1977) compared the difference between an intensive weekend psychodrama experience and six spaced (once-aweek) sessions. In the study, 54 female nursing students were randomly assigned to the weekend group, the spaced-psychodrama group, or to the control group. Both the weekend and the spaced-session group continued for 18 hours. The results indicated that although the intensive-weekend group significantly reduced feelings of anxiety, depression, and distress, no significant effects were noted for the spaced-session group. Dadsetan et al., (2008) randomly selected 16 children (10-11 years) to receive weekly 2-hr sessions of drama therapy for 6 weeks. At the end of the 6 weeks, the children reported significantly lower scores on the Liebowitz Social Anxiety Scale for Children and Adolescents (LSAS-CA) than the control group (Liebowitz et al., 1999).

\section{CONCLUSION}

In sum, it can be concluded that psychodrama can lead to improvement in life of juvenile delinquents as decreases the level of anxiety and depression. It seems that changes in cognitive insight, consciousness level, indirect training of social skills, depth and scope of individual experiences, understanding self strengths and weaknesses, bringing an emotional and cognitive integrity, and catharsis are the key reasons for the change in behaviour.

\section{Study Limitations}

Single-sex sample and small sample size that provides a problem for generalized results. It is suggested that for future studies of both sexes in a larger volume samples be used. And also it is recommended that research projects on juvenile delinquent can do on broad level like different institutions.

\section{Acknowledgments}

The author thanks all the Juvenile Delinquents who participated and cooperated in this research.

\section{REFERENCE}

Blatner, A. (2005). Acting-in: practical applications of psychodramatic methods. Tehran: Roshd. (persian).

Coleman, J. S. (1990). Foundation of social theory. Cambridge, MA: Harvard University.

Ebrahimi, B. F. (2011). The effect of psychodrama on depression among women with chronic mental disorder. European psychiatry, 26(1), 621.

Friedlander K. (1945). The psychoanalytical approach to juvenile delinquency. New York, NY: International Universities. 


\section{Effect of Psychodrama Therapy on Depression and Anxiety of Juvenile Delinquents}

Ghasempoor A, Mahdavi A. (2010). Survey Effect of psychodrama on promoting public health. Journal of Rahpooye of Art 3(9), 11-20.

Gibbons DC. (1968). Society, crime and criminal careers. New Jersey: Prentice Hall.

Glueck, S., and Eleanor Glueck (1950). Unraveling Juvenile Delinquency. Cambridge, MA: Harvard University.

Hall, I. (1977). The effects of an intensive weekend psychodrama 'Is. spaced psychodrama sessions on anxiety, distress and attitude toward group interaction in nursing students. Unpublished doctoral dissertation, University of New Mexico.

Hamamci, Z. (2006). Integrating psychodrama and cognitive behavioral therapy to treat moderate depression. The arts in psychotherapy, 33(3), 199-207.

Johnson EH. (1996). Crime, correction and society. Illinois: Dorsey.

Ozdel, O., Ergin, S., Kacar, N. (2010). Psoriasis hastalarında psychodrama: stres ve stresle baş etme. Anadolu Psikiyatri Dergisi, 11(3), 220-227.

Rajabi, GR. (2007). Psychometric Properties of Beck Depression Inventory. Journal of Developmental Psychology: Iranian Psychologists, 20(4).

Rosenhan DL, Seligman ME. (1995). Abnormal psychology. New York, NY: WW Norton \& Co.

Somov .P.G. (2008). Psychodrama group for substance use relapse prevention training. The Arts in Psychotherapy, 35,151-161.

William W.K. Zung. (1971). A rating instrument for anxiety disorders. Psychosomatics.

How to cite this article: Sharma N (2017). Effect of Psychodrama Therapy on Depression and Anxiety of Juvenile Delinquents. International Journal of Indian Psychology, Vol. 5, (1), DIP: 18.01.124/20170501, DOI: 10.25215/0501.124 